\title{
LAS ENTRAÑAS DE UN CUENTO
}

A Laura Vargas Villaveces para que siga escribiendo.

Todo autor, por detrás de una muralla de explicaciones y de teorías que ha leído y que incluso sostienen su narrativa, esconde un núcleo sobre el que pocas veces reflexiona por la dificultad de hacerlo. Primero, y hay que plantearlo, no exis te una receta o un camino que pueda contener las posibilidades de resolución de una historia. Esto tiene un sentido, puesto que implica el uso primordial de la intencionalidad, de la imaginación cargada o subordinada por los afectos, lo que determina el curso inicial de un cuento. El juego de ajedrez, las posibilidades que pueden surgir, ese granito que se dobla sesenta y cuatro veces y cuya cifra que, para desconcierto del príncipe que ha ofrecido pagarlo al sabio y que se da cuenta de que con todas sus riquezas no lo conseguirá, es un pálido reflejo de las infinitas posibilidades que tiene un cuento.

Recuerdo esa frase de Anäis Nin quien decía que un escritor puede hacerle el amor a cualquier cosa. Basta con extrapolar a otras actividades para descubrir el horizonte de matices de la interacción, de variaciones, de escenarios y de personajes, entre otros as pectos que pudieran subyacer a la estructura del cuento. El verbo es condicional, puesto que es el autor quien siente la his toria y sin mucha previsión, con unos cuantos amarres y con alguna luz en el fondo de esa caverna de palabras tiene que avanzar con paso incierto, dubitativo, como un músico que pulsa las notas de una pieza que improvisa y que está dispuesto a dar marcha atrás, a reacomodar sus esfuerzos o a seguir esa veta que recién descubre como adecuada. Nada que ver esto con la fría concepción de Edgar Allan Poe, asunto del cual no me voy a ocupar, pero que sólo responde a uno, entre muchos métodos de composición narrativa y que en mi opinión son usados con éxito tan sólo parcialmente.

Vadimir Propp o de otra foma más didáctica, Gianni Rodari, no le funcionan a un escritor que ya ha recorrido cierto trecho en el arte creativo, pues sus ideas, en un caso, o sus ejercicios, en el otro, empobrecen sus posibilidades de libertad creativa y, por ende, de descarga emocional. El pozo de donde brotan los cuentos, la interioridad del autor y la obra es un pedazo organizado de esa interioridad, no importa el método ni el tono, pues en algunos el producto tendrá matices cómicos, en otros será juguetón, dramático, lírico, entre otros.

\footnotetext{
*Escritor y narrador con varias novelas publicadas, entre ellas Enamoraticum y El Conde de Cuchicute, a más de numerosos cuentos, la
} may oría inéditos. 
No es necesario citar directamente a Walter Benjamin en El narrador para comprender que, de un modo general, la cultura produjo los cuentos para nombrar con un sentido pleno, vívido, totalizante y compartido, las cosas que no podía explicar del entomo. Los cuentos populares condensaban la sabiduría del pueblo y se convertían en los vehículos más apropiados para su socialización. Para una cultura escrita, que ha perdido en buena parte el poder de la conversación, el cuento es la propia voz del individuo ais lado que se sumerge en una recreación de $X$ aspecto de la vida, aspecto que podría llamarse su faro, su corazón, su expresión más íntima con la que quiere dar una opinión indirecta a una cultura que no siempre escucha. El cuento es una interpretación del mundo des de los deseos personales del autor solitario, quien puede que ya tan sólo esté ensimismado atendiendo a su propia voz.

Una historia se produce como el manejo de la intención del autor, quien presenta una perspectiva que contrasta de algún modo con las previamente establecidas por la cultura. Esto sucede incluso cuando el autor se solaza con juegos de palabras no secuenciales, con juegos conceptuales o una intención esteticis ta que se recarga muchísimo más en la forma que en el contenido.

\section{2}

¿Qué es lo que hace que se escoja un tema y no otro? La palabra "tema" es de por sí una sofisticación, una especialización de quien ya "sabe" del asunto y que percibe que tiene que poseer un cierto elemento estético que diferencie o relacione de otro modo su propuesta - por indirecta y sutil que sea- con el sentido que comunmente se le otorga a las cosas. El escritor, lo afirmó Nikos Kazantzakis en su maravilloso libro Carta al greco, va agudizando su sentido de observación y de condensación y le basta salir a la esquina a comprar el pan y la leche para encontrarse con una idea, con una historia que contar. Pero, más primitivamente, se puede hablar de "disparadores", de hechos o relaciones que inducen a una descarga expresiva que se llega a conformar como un aparato narrativo.

Se puede tener el tema dispuesto y éste hasta puede encontrarse prefijado y ya listo, pero eso no basta para producir un cuento de calidad. Se requiere que el autor se apodere del material, que lo haga suyo. Esto no es posible enseñarlo; tal vez, tan sólo tratar de inducir una pers pectiva personal. Los niños pueden hacerlo con Rodari, mas no los adultos que están más conscientes de la intención del juego. El manejo del tema requiere un desprendimiento existencial, un abandono que puede producir el milagro de una espontaneidad contenida, llena de significados y de posibilidades.

En los cuentos sobre desplazados, Lugares ajenos, convocado y publicado por EAFIT, se siente que tener el tema no bastó a más de uno de los autores, no a todos, porque, a su vez, varios de los cuentos logran un mundo propio, un universo cerrado y abierto en su interioridad enriqueciendo con su expresión 
nuestra escasa literatura social. Este tipo de literatura es la que más evidencia el hecho de que no basta tener un tema, que no basta querer, si no que más bien ese tipo de intentos obliga a que en la práctica artística se tenga que saber modularlos, traducirlos es tética y emocionalmente.

Se siente en algunos cuentos malogrados, pese al interés que pudiera sugerir el tema, cierto manejo racional, cierta sorpresa que no es eficiente, que no tiende a ampliar la frontera expresiva. La principal dificultad derivada del tratamiento de un tema es convertirlo en "tarea", en encargo, en la obligación racional o social de resolver una temática. Esto es un asunto que obliga a meditar lo inasible de la creación narrativa que no está tan obligada a "decir" como sí lo puede ser en un artículo o en un ensayo.

El tema crudo cuando desnuda la intención del autor, cuando no da más que una somera o esquemática interpretación o cuando hace evidente el pobre trasfondo en vez de "abrirlo" en vez de convertirlo en una caja de sorpresas, en una caja de pandora, en un infinito emocional. El cierre temprano de la interpretación en el cuento, induce los efectos, los hace es perados, previsibles, los empobrece en vez de potenciarlos. Una temática es, de hecho, muy simple, como el argumento y la fábula de un cuento; pero puede poseer un cierto tipo de compromiso emocional, con una distancia estética particular, que potencia las implicaciones de una anécdota aparentemente muy pobre. En el otro caso, pareciera más bien que se quiere inconscientemente controlar la lectura y no dar cabida a otras asociaciones, empobreciendo la calidad estética de la historia. El manejo temático implica cierto descontrol, cierta libertad de los contenidos para vivir autónomamente con respecto a la intención original del autor. Por ello los narradores suelen ser tan benévolos como los poetas y suelen reírse de las interpretaciones que suceden a sus obras, pues no fueron contempladas racionalmente en el momento de la creación.

Se puede tener una idea, pero se requiere de la frase, y ésta no controla el sentido completo del texto. Ese sentido tiene que aparecer y el autor se solaza en el momento de la escritura y de la relectura. La obra, la narración, va cobrando una vida inesperada que no necesariamente significa una pérdida de la guía propues ta en el texto por el autor. Él está dejando que el cuento cobre vida desde adentro.

Desde ese uso poderoso y autónomo de las palabras y de las frases, que van reconstruyendo y transformando las intenciones primarias del autor se suele definir un cuento. En esto el narrador no se diferencia demasiado del poeta. Sólo que su prosa es un transcurrir que se convierte en río turbio, en donde importan los hechos, los personas, las situaciones, y no en un remanso de perfección en las frases. Al menos no tiende a ello. La historia que comienza ha de resolverse, según los elementos de "gramática" narrativa que proponga. En esas primeras frases se juega el punto de vista del narrador, el tipo de estructura textual que a de surgir, el epos mismo y esto no puede tampoco enseñarse. De hecho un autor puede tardar años en encontrar las palabras, el ambiente, las sensaciones, que es lo que esconden las mismas palabras. Con razón Hemingway menciona como una 
dificultad, al dejar de escribir temporalmente un texto narrativo, no dejarlo en punta, no dejar lo que en teatro llama el "pie", pues la narración se enreda emocionalmente y recomenzar puede significar una labor que se retarda, que se pospone indefinidamente o que se hace imposible.

Por supuesto, estas observaciones valen para la novela también. La imaginación creadora aparece en el manejo de un tema y se apodera de él, impidiendo el control total de la razón. No se pueden prever tan precisamente como algunos quisieran los mundos de la imaginación. Desencadenada ésta surge un vórtice en el que, como un hábil jinete, el narrador en su soledad, ha de saber montar para poder conducirla a buen término. La his toria ha de cerrarse sobre sí misma en un ambiente que se llena de caracteres y de elementos para constituirse en un sistema autónomo, abierto, que contiene una suma de riquezas que sólo en el momento de la lectura podrán degustarse.

Calvino, refiriéndose a las fábulas y mitos orales, que contenían una serie de palabras que al ser pronunciadas, ya en desorden, ya porque surgía una palabra nueva, se desencadenaba un secreto terrible que impactaba en los escuchas. El cuento, si no desencadena nada significativo en los lectores, si no busca arrastrarlos, y si no cuenta, también con su complicidad y colaboración, pierde valor pese a la importancia "estratégica" de los contenidos.

He mencionado la palabra ambiente, atmósfera, y ésta me lleva a aquello que hace convincente, sugeridora y expresiva una historia frente a otra que puede estar surgiendo en la vida cotidiana. El escritor no debe dejarse engañar por autores despistados que creen que al repetir un hecho sucedido no lo están transformando, una his toria posee o no al ser escrito un "algo" que la hace nueva, irrepetible, que la hace un artificio que puede llegar a convertirs e con el tiempo en la "realidad".

El escritor tiene que poseer al respecto demasiado sentido común para entender qué es posible y qué no en un cuento que quiere ser verosímil; pero, a su vez, ha de tener suficiente capacidad de riesgo para desbaratar algún hilo de eso que se convierte en previsible, en ya realizado, para que su historia no conduzca a lo establecido, para que diverja de ese mismo sentido común. A este respecto me encuentro muy alejado del clisé obligado de un final sorprendente, y no me refiero necesariamente al cuento fantástico. El cuento contemporáneo juega con otras posibilidades. La idea de Cortázar del knocaut ha sido malinterpretada. Quisiera creer que lo que pretende es presentar una sorpresa eficiente, la que no tiene que ser una sorpresa física, anecdótica ni siquiera una frase brillante y por eso adocenada. No sólo Raymond Carver realiza este tipo de cuentos. En Colombia encontramos a un delicioso autor, a Ramón Illan Baca, con finales que abren la obra para que el lector la concluya, para que se ría, para que saque conclusiones o, mejor, para que la historia, como la vida, se difumine dejando una estela de 
sensaciones como un aroma que se dispersa o como un color que se degrada o como un momento de la cotidianidad.

Algunos escritores, temerosos porque no escriben o porque temen hacerlo y porque no se desprenden de su angustia, plantean que un principio en un cuento debe arrasar y qué no decir del final: una pequeña explosión de sabor narrativo. Pero lo que sostiene un cuento es su tono, su ritmo y su concordancia expresiva.

En particular, quiero enfatizar el concepto de tono. Recordemos que el tono es la modulación y que ésta le imprime un estado de ánimo a la voz humana y ese estado es el que encierra el mundo existencial. En el caso de una obra narrativa es indispensable que logre algún tipo definido de modulación existencial, si no se aplanaría, se perdería como expresión. El núcleo de la obra narrativa es esta gramática significativa que tiene que convencer, pues se articula de tal modo que seduce al lector. Ya, por un experimento sensorial y expresivo; ya por un juego de taller de escritores, por una simulación; ya porque se "da" simplemente. En general, sin embargo, se puede afirmar que las recetas en este campo no existen.

El ambiente es el resultado de la combinación de los elementos que utiliza el autor. Estos elementos tienen una relación directa con sus preferencias, con sus maneras de leer el mundo. De allí surgen las formas genéricas, también, y no sólo por los aspectos históricos. Esa capacidad para escoger, debida a las influencias, a la sensibilidad, a la capacidad de imaginar un entorno y al gus to por ponerlo en evidencia, es la síntes is que permite construir un mecanismo narrativo apropiado. Esto tampoco se puede enseñar, así existan ejercicios que permiten componer de un modo mecánico; por ejemplo, produciendo un giro ines perado, proponiendo un ayudante, etcétera.

Las adaptaciones realizadas por Disney de algunos cuentos clásicos revelan, pese a los efectos y a las magníficas caricaturas, esta falta de carácter y de compromiso con la historia y con los personajes. Estos proyectos se hacen repetitivos, adocenados, lo que en una cultura escrita y audiovisual es una pérdida si consideramos el arte como uno de los caminos, junto con la ética, para la construcción, renovación y creación de nuevos matices existenciales. Me refiero a la ampliación de la frontera de conciencia humana, a la ampliación de lo que significa ser seres autoreferidos o seres genéricos en el sentido de Marx de los Manuscritos de Economía y filosofía.

Un ambiente, una atmósfera se crea de tal modo y no de otro porque al autor no le queda mejor camino para proponer y porque, en síntesis, necesita hacerlo así. Los mejores cuentos surgen de este compromiso con los recursos que emplea. El autor puede arriesgarse a la exageración, a la amplificación unilateral de un factor, pero porque intuye los efectos que intenta lograr.

Cada cuento tiene un repertorio de efectos y unos pocos caminos para poder lograr algo al respecto. La atmósfera no es sólo la coherencia interna, es lo que hace que la intención del autor se logre. Para ello se tiene que tener una mínima conciencia del público lector que se puede esconder en el texto, al cual finalmente 
podrá ir dirigido. Así se equivoque a este respecto, el autor está adentro y afuera de su historia. Sabe que va a ser leído, sabe que puede forzar la verosimilitud introduciendo un elemento de absurdo que incita a la curiosidad o, al menos, que permite misteriosamente mantener la lectura del texto.

Cuando una historia contiene una complejidad significativa, incluso en la simplicidad más grande o, en el caso contrario, en el abigarramiento, se ha inventado un soporte, una atmósfera que le otorga un "tono" al texto, entonces, se puede afimar que el cuentista ha logrado ambientar de un modo adecuado su proyecto narrativo. Puede ser calidez, exotismo, sensualidad, angustia, misterio, entre otros, pero el cuento se sostiene y produce efectos colatelares como ciertas medicinas. El texto madura hasta donde es posible, luego se irá diluyendo. Su pretendida atmósfera se hará distinta, muy poética, diferenciada, primero, quizá; luego se hará muy representativa de una época; y, finalmente, se hará, por ejemplo, muy desusada, una joya extraña o, definitivamente, demasiado tonta. Éste es uno de los riesgos que se pres entan al crear atmósferas, así como pueden sostenerse por mucho tiempo, suelen también desaparecer y banalizar una tensión que se pretendía seria, dramática, etcétera. El artista tiene que intentarlo siempre para poder crear historias de valor. Como cuentista prepara en cada historia un coctel de diversos sabores, a veces con alcohol, en otras ocasiones con zanahoria u otros elementos más protocolarios que reales, y con esa propuesta -en su libertad vital-se planta a esperar el mordis co de los lectores.

Quedan muchos aspectos por desarrollar, desde el asunto del canon, de los géneros y subgéneros de la narrativa, del estilo, entre otros, que dejo por ahora de lado. 